\title{
EFFECT OF IRON SUPPLEMENTATION ON THE EROSIVE POTENTIAL OF CARBONATED OR DECARBONATED BEVERAGE
}

\author{
Melissa Thiemi KATO ${ }^{1}$, Andrea Gutierrez MARIA ${ }^{2}$, Luís Guilherme Matiazi VAZ ${ }^{2}$, Flávia de Moraes ITALIANI \\ Sílvia Helena de Carvalho SALES-PERES ${ }^{4}$, Marília Afonso Rabelo BUZALAF ${ }^{5}$
}

\author{
1- DDS, MSc, Graduate student (Master's degree Program), Department of Social Dentistry, Bauru School of Dentistry, University of São \\ Paulo, SP, Brazil, \\ 2- DDS, Undergraduate student, Department of Biological Sciences, Bauru School of Dentistry, University of São Paulo, Bauru, SP, Brazil. \\ 3- DDS, MSc, Graduate student (Master's degree Program), Department of Biological Sciences, Bauru School of Dentistry, University of São \\ Paulo, Bauru, SP, Brazil. \\ 4- DDS, MSc, PhD, Associate Professor, Department of Social Dentistry, Bauru School of Dentistry, University of São Paulo, Bauru, SP, Brazil. \\ 5- DDS, MSc, PhD, Associate Professor, Department of Biological Sciences, Bauru School of Dentistry, University of São Paulo, Bauru, SP, Brazil. \\ Corresponding address: Marília Afonso Rabelo Buzalaf - Departamento de Ciências Biológicas - Faculdade de Odontologia de Bauru, \\ Universidade de São Paulo. Al. Octávio Pinheiro Brisolla, 9-75. Bauru-SP, Cep.: 17012-901, Brasil - phone: + 551432358246 . fax: + 5514 \\ 32262076. e-mail: mbuzalaf@fob.usp.br \\ Received: August 14, 2006 - Modification: November 23, 2006 - Accepted: February 05, 2007
}

\begin{abstract}
$T_{\text {his }}$

study evaluated, in vitro, the effect of iron (previously exposed with enamel powder or added directly to the beverage) on the erosive potential of carbonated or decarbonated beverage. Four sets of experiments were done. For groups E1 and E3, a solution containing $30 \mathrm{mmol} / \mathrm{L} \mathrm{FeSO}_{4}$ was added to bovine enamel powder (particles between 75-106 mm) before exposure to the carbonated or decarbonated beverage (Sprite Zero ${ }^{\circledR}$ ), respectively. For groups $\mathrm{E} 2$ and $\mathrm{E} 4,15 \mathrm{mmol} / \mathrm{L} \mathrm{FeSO}_{4}$ was added directly to the carbonated or decarbonated beverage, respectively. Control groups were included for comparison. In controls $\mathrm{C} 1$ and $\mathrm{C} 3$, the experiments $\mathrm{E} 1$ and $\mathrm{E} 3$ were repeated, but the iron solution was replaced by deionized water. For controls $\mathrm{C} 2$ and $\mathrm{C} 4$, the carbonated and decarbonated beverage, respectively, was used, without addition of iron. After addition of the beverage to the powdered enamel ( $40 \mathrm{mg}$ enamel powder $/ 400 \mu \mathrm{L}$ of final volume), the sample was vortexed for $30 \mathrm{~s}$ and immediately centrifuged for $30 \mathrm{~s}(11,000 \mathrm{rpm})$. The supernatant was removed after $1 \mathrm{~min} 40 \mathrm{~s}$. This procedure was repeated in quintuplicate and the phosphate released was analyzed spectrophotometrically. The results were analyzed by Student's t-test $(\mathrm{p}<0.05)$. E2 presented the best results with a significant inhibition (around 36\%) of phosphate released. For E3 and E4 a non-significant inhibition (around 4 and 12\%, respectively), was observed. For E1 an increase in phosphate loss was detected. Thus, the protective effect of iron seems to be better when this ion is directly added to the carbonated beverage.
\end{abstract}

Uniterms: Tooth erosion; Demineralization; Iron; Dental enamel.

\section{INTRODUCTION}

Several studies have shown the protective effect of iron on enamel demineralization ${ }^{2,8,10-14,16,18}$. Many hypothetical mechanisms have been proposed to explain this protective effect, but the precise mechanisms remain unclear.

Some preliminary studies conducted at our laboratory suggest that the presence of increasing iron concentrations can inhibit the dissolution of bovine enamel powder under acidic conditions, with the best protection around $15 \mathrm{mmol} /$ $\mathrm{L} \mathrm{FeSO}_{4}{ }^{5}$. Thus, it has been speculated that the supplementation of foods and beverages with iron could be an alternative strategy to reduce not only dental caries, but also dental erosion. This would also help preventing anemia, which is another important public health problem ${ }^{6}$.

Trying to find a preventive method for dental erosion, our research group is currently investigation the addition of iron in carbonated beverages, which have been shown to have a high erosive potential ${ }^{19}$. However, before these experiments could be conducted, important questions have arisen. The first question was related to the possible influence of the presence of carbonate on the protective effect of iron given that the removal of carbonate would make easier to pipette samples, but, on the other hand, could change the beverage $\mathrm{pH}$. The second question refers to the moment at which iron would exert its protective effect: whether when previously added to enamel, or when directly added to the beverage. This study was designed to analyze these 
situations. The null hypotheses tested were: a) the absence of carbonate does not alter the protective effect of iron on the inhibition of enamel demineralization and b) the protective effect of iron on enamel demineralization is not influenced by the moment when it enters in contact with enamel.

\section{MATERIAL AND METHODS}

\section{Bovine enamel powder preparation}

Fragments of enamel were obtained from bovine incisors. The teeth were sterilized by storage in $10 \%$ formalin buffered

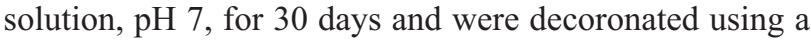
diamond disk (Isomet 1000; Buehler, Lake Bluff, IL, USA). Next, using three parallel diamond disks separated by two 4 mm spacers, 8-10 fragments were cut from the crown of each bovine incisor. About one hundred enamel slabs (4 X $4 \mathrm{~mm})$ were obtained and these fragments had their dentin totally removed by abrasion. The surfaces of the fragments were flattened with 300- and 600-grit $\mathrm{AL}_{2} \mathrm{O}_{3}$ papers and were ground in a stainless pestle and mortar (KM1, model MLW, Hergerstellt, Germany). From the enamel powder, particles between 75 and $106 \mu \mathrm{m}$ were selected using appropriate meshes.

\section{Experimental design}

The chosen beverage was Sprite Zero ${ }^{\circledR}$ because it has been reported to have a strong buffer capacity ${ }^{20}$. Firstly, its $\mathrm{pH}$ was analyzed (pHmeter MB10 (Marte Balanças e Aparelhos de Precisão Ltda, Santa Rita do Sapucaí, MG, Brazil) with and without carbonate. When necessary, carbonate was removed by leaving $150 \mathrm{~mL}$ of beverage in a vacuum pump for $1 \mathrm{~h}$.

The experimental phase was divided into four sets of experiments. In the first two sets the beverage containing carbonate was used. The difference between the two sets was that in the first one, the powdered enamel was previously exposed to the iron and then to the beverage (E1), while in the second one, the iron was added directly to the beverage (E2). In the other two sets (E3 and E4), the beverage was decarbonated, as mentioned above. In E3 the powdered enamel was previously exposed to the iron and then to the beverage, and in E4 the iron was added directly to the beverage. The procedure was repeated five times $(n=5)$ for each group.

In E1, at time zero, $40 \mathrm{mg}$ of powdered enamel was initially added to $0.20 \mathrm{~mL}$ of $30 \mathrm{mmol} / \mathrm{L} \mathrm{FeSO}_{4}$ and $0.20 \mathrm{~mL}$ of the carbonated beverage (Sprite Zero ${ }^{\circledR}$ with carbon dioxide) was immediately added $(0.40 \mathrm{~mL}$ of the beverage at $15 \mathrm{mmol} / \mathrm{L}$ $\mathrm{FeSO}_{4} / 40 \mathrm{mg}$ enamel powder). The sample was vortexed for $30 \mathrm{~s}$ and immediately centrifuged for more $30 \mathrm{~s}(11,000 \mathrm{rpm})$ and the supernatant was removed after 1 min $40 \mathrm{~s}$.

In E2, at time zero, $40 \mathrm{mg}$ of powdered enamel was added to $0.40 \mathrm{~mL}$ of carbonated beverage, containing $15 \mathrm{mmol} / \mathrm{L}$ $\mathrm{FeSO}_{4}$, following the same sequence mentioned above: agitation, centrifugation and the removal of supernatant.

Experiments E3 and E4 followed a protocol virtually identical to E1 and E2, respectively, except for the use of the decarbonated beverage.

For comparison, controls groups were included. In controls $1(\mathrm{C} 1)$ and $3(\mathrm{C} 3)$, the experiments E1 and E3 were repeated, but the iron solution was replaced by deionized water. As for controls 2 (C2) and 4 (C4), pure beverage was used, with and without carbonate, respectively.

\section{Phosphate analysis}

In order to determine the amount of dissolved enamel, the phosphate released in the supernatant was analyzed colorimetrically, in duplicate, using the Fiske-Subarrow ${ }^{9}$ method (Cary 50, Pharmacia Biotech, Cambridge, England).

Samples containing various iron concentrations were read against standard phosphate solutions containing 0.75 , 1.5, 3.0, 6.0, 12.0 and $24 \mu \mathrm{g}$ P. The absorbance readings were converted to $\mu \mathrm{g}$ phosphate using a standard curve with a coefficient correlation of $r \geq 0.99$. All samples were analyzed in duplicate. The mean repeatability of the readings, based on duplicate samples, was $97.0 \%$.

The phosphate concentration in experimental group was normalized to the respective control group (without iron).

\section{Statistical Analysis}

GraphPad Instat software (GraphPad Instat Inc., San Diego, CA, USA) was used. After checking the normality and homogeneity, the results were analyzed by Student's ttest for comparison between each experimental group and its respective control. The same test was also used for twoby-two comparisons, as follows: E1 X E3, E2 X E4, C1 X C3 and $\mathrm{C} 2 \mathrm{X}$ C4. Significant level was set at 5\%.

\section{RESULTS}

Table 1 shows the amount of phosphate released from the enamel powder for the experimental and control groups and also the dissolution rate of the experimental group as a function of the dissolution rate of the respective control group. Experiment E2 showed the best results, with a significant inhibition (36\%) of the enamel dissolution when iron was added $(\mathrm{p}<0.05)$. For experiments E3 and E4 a slight inhibition of enamel dissolution was found when iron was added ( 4 and $12 \%$, respectively), but the experimental groups did not differ significantly from the respective control groups ( $p>0.05$ ). As for experiment E1, an increase in mineral loss was observed in comparison to its respective control (C1).

When the presence of carbonate was considered, no significant differences were detected between experiment E1 (presence of carbonate) and experiment E3 (absence of carbonate) $(\mathrm{p}>0.05)$, as well as between experiments E2 (presence of carbonate) and E4 (absence of carbonate) $(p>0.05)$. The same was observed for the respective control groups (C1XC3 and C2XC4). Direct comparisons between other groups (e.g.: E1XE2, E1XE4, E2XE3, C1XC2, C1XC4 and $\mathrm{C} 2 \mathrm{XC} 3$ ) were not adequate because the experiments were designed differently.

The $\mathrm{pH}$ of the soft drink before and after removing the 
carbonate dioxide remained unaltered (2.65), but the protective effect of iron on the enamel dissolution was reduced (Groups E1 compared to E3 and E2 compared to E4) when the carbonate was removed (Table 1).

The analysis of Table 1 shows that the dissolution rate was smaller when iron was added directly to the beverage, in comparison to the respective control.

\section{DISCUSSION}

The results of various in vitro studies suggest that the presence of increasing iron concentrations can inhibit the dissolution of enamel under the acidic conditions $\mathrm{s}^{3-5}$. A recent in situ study has shown that a $10 \mathrm{mmol} / \mathrm{L}$ iron rinse prior to an acidic challenge with $\mathrm{Coke}^{\circledR}$ can reduce the superficial microhardness change and wear of human enamel and dentin blocks ${ }^{19}$. The mechanism involved in this protection of iron against mineral dissolution is not completely understood. Torell ${ }^{22}$ reported that when enamel is incubated with ferrous salt solutions, acid-resistant enamel surfaces are established due to the precipitation of ferric phosphates on the enamel surface, due to the combination of ferric ions with phosphate ions dissolved on enamel surface. The formation of this ferric phosphate barrier was also suggested in recent in situ studies simulating a high cariogenic challenge ${ }^{11}$ and erosive/ abrasive challenges ${ }^{19}$. Other possible explanations have been suggested, such as participation in the remineralization of human enamel and in the nucleation of apatite ${ }^{1,17}$, replacement of calcium in apatite ${ }^{15,17}$, increased concentration in remineralized dentin and enamel caries lesions ${ }^{7,21}$ and inhibition of demineralization ${ }^{1}$.

In this study, we evaluated some variables that could influence the effect of iron on the inhibition of enamel dissolution by an acidic soft drink. One of the tested variables was the presence or absence of carbonate. This variable was tested because in preliminary experiments, it was observed that, in the presence of carbonate, there was bubble formation in the pipette, which could alter the final volume of the samples. However, it was hypothesized that the removal of carbonate would cause changes in the $\mathrm{pH}$, which, in turn, could interfere with the effect of iron on enamel. It was observed, however, that although the $\mathrm{pH}$ remained unaltered after the carbonate was removed, the protective effect of iron on the enamel dissolution was reduced (Groups E1 compared to E3 and E2 compared to E4). The reasons why this reduction on the protective effective of iron occurs when the carbonate is removed cannot be answered by the protocol of this study, but this observation is useful for future studies involving the addition of iron to carbonated beverages. Thus, even though the presence of carbonate can make more difficult the pipetting of the samples, it should not be removed when the addition of iron to the beverage is under test. It must be highlighted that the presence of carbonate in the beverage represents the "real" situation when the beverage is consumed. This is another positive point to the addition of iron in carbonated beverages as a preventive measure for enamel erosion.

The other variable tested in this study was the moment at which the iron should get in contact with enamel in order to reach its maximum protective effect. For this purpose, we tested the addition of iron to the enamel before the exposure to the beverage, compared to the addition of iron directly to the beverage. It was observed that the dissolution rate was smaller when iron was added directly to the beverage. This facilitates the use of iron for prevention of enamel demineralization because it can be added directly to acid beverages and does not seem to require a pretreatment of the enamel, such as rinsing, for example.

The results of the present study showed that the best protective effect of iron when added to a soft drink, regarding the prevention of enamel dissolution, is reached when the soft drink is carbonated and iron is added directly to the

TABLE 1- Means $( \pm S D)$ of the amount of phosphate released $(\mu \mathrm{g})$ from enamel powder exposed to Sprite Zero ${ }^{\circledR}$ containing or not carbonate as a function of the presence of iron previously exposed with the enamel powder or added directly to the beverage

\section{Groups Control* $\left(\mathrm{C}\right.$ - without $\left.\mathrm{FeSO}_{4}\right) \quad$ Experimental $^{* *}\left(\mathrm{E}-\right.$ with $\left.15 \mathrm{mM} \mathrm{FeSO}_{4}\right) \quad$ Alteration of dissolution rate**}

\begin{tabular}{llll}
1 & $18.07 \pm 2.39^{\mathrm{A}}$ & $22.78 \pm 4.63^{\mathrm{A}}$ & $+26 \%$ \\
2 & $33.48 \pm 0.95^{\mathrm{A}}$ & $21.18 \pm 0.42^{\mathrm{B}}$ & $-36 \%$ \\
3 & $19.80 \pm 3.09^{\mathrm{A}}$ & $18.98 \pm 1.85^{\mathrm{A}}$ & $-4 \%$ \\
4 & $33.66 \pm 0.62^{\mathrm{A}}$ & $29.61 \pm 8.17^{\mathrm{A}}$ & $-12 \%$ \\
\hline
\end{tabular}

* For groups $\mathrm{C} 1$ and $\mathrm{C} 3$, the experiments $\mathrm{E} 1$ and $\mathrm{E} 3$ were repeated, but the iron solution was replaced by deionized water. For controls $\mathrm{C} 2$ and $\mathrm{C} 4$, the carbonated and decarbonated beverage, respectively, was used, without addition of iron.

${ }^{* *}$ For groups E1 and E3, bovine enamel powder was incubated with the solution containing iron before exposure to the carbonated or decarbonated beverage (Sprite Zero ${ }^{\circledR}$ ), respectively. For groups E2 and E4, iron was added directly to the carbonated or decarbonated beverage, respectively.

${ }^{* * *}+$ and - numbers, indicate, respectively, increase and decrease of dissolution rate of experimental groups when compared to the corresponding control groups.

Different letters in the same line indicate statistically significant difference between the experimental groups and their respective control groups. 
beverage. Thus, in further studies this protocol should be followed.

\section{CONCLUSION}

In conclusion, the removal of carbonate from the soft drink reduced the protective effect of iron on enamel dissolution; the moment at which the iron got in contact with enamel also influenced this process. Thus, both null hypotheses formulated were rejected.

\section{ACKNOWLEDGEMENT}

The authors would like to acknowledge The São Paulo State Research Foundation (FAPESP) for financial support (Grant n. 04/12632-2).

\section{REFERENCES}

1- Bachra BN, Van Harskamp GA. The effect of polyvalent ions on the stability of a buffer system for calcification in vitro. Calcif Tissue Res. 1970;4:358-65.

2- Bowen WH, Pearson SK. Residual effects of fluoride on a severe cariogenic challenge in rats. Caries Res. 1994;28(4):246-50.

3- Brookes SJ, Robinson C, Shore Rc, Kirkham J. Inhibitory effect of metal ions on acid demineralization [abstract 132]. Caries Res. 2004;38(4):401. Presented at 51st Annual ORCA Congress; 2004 June 30-July 3; Marburg, Germany.

4- Brookes SJ, Shore RC, Robinson C, Wood SR, Kirkham J. Copper ions inhibit the demineralisation of human enamel. Arch Oral Biol. $2003 ; 48(1): 25-30$.

5- Buzalaf MAR, Italiani FM, Kato MT, Martinhon CCR, Magalhães AC. Effect of iron on inhibition of acid demineralization of bovine dental enamel in vitro. Arch Oral Biol. 2006;51(10):844-8.

6- DeMaeyer E, Adiels-Tegman M. The prevalence of anaemia in the world. World Health Stat Q. 1985;38(3):302-16.

7- Driessens FC, Theuns HM, Heijligers HJ, Borggreven JM. Microradiography and electron microprobe analysis of some natural white and brown spot enamel lesions with and without laminations. Caries Res. 1986;20(5):398-405.

8- Dunning JC, Ma Y, Marquis RE. Anaerobic killing of oral streptococci by reduced, transition metal cations. Appl Environ Microbiol. 1998;64(1):27-33.

9- Fiske CH, Subarrow Y. The colorimetric determination of phosphorus. J Biol Chem. 1925;66:375-400.

10- Kato MT, Italiani FM, Martinhon CCR, Buzalaf MAR. Estudo in vitro do efeito inibidor de três diferentes sais na desmineralização do esmalte dentário bovino [resumo Pa091]. In: Anais da 22a Reunião Anual da Sociedade Brasileira de Pesquisa Odontológica - SBPqO; 2005 set. 3-7; Águas de Lindóia, SP. São Paulo: SBPqO; 2005. p. 122.

11- Martinhon CCR, Italiani FM, Padilha PM, Bijella MFTB, Delbem $\mathrm{ACB}$, Buzalf MAR. Effect of iron on bovine enamel and on the composition of the dental biofilm formed "in situ". Arch Oral Biol. 2006;51(6):471-5.
12- Miguel JC, Bowen WH, Pearson SK. Effects of frequency of exposure to iron-sucrose on the incidence of dental caries in desalivated rats. Caries Res. 1997;31(3):238-43.

13- Miguel JC, Bowen WH, Pearson SK. Effects of iron salts in sucrose on dental caries and plaque in rats. Arch Oral Biol. 1997;42(5): 377-83.

14- Miguel JC, Bowen WH, Pearson SK. Influence of iron alone or with fluoride on caries development in desalivated and intact rats. Caries Res. 1997;31(3):244-8.

15- Okasaki M, Takahashi J, Kimura H. Iron uptake of hydroxyapatite. J Osaka Univ Dent Sch. 1985;25:17-24.

16- Pecharki GD, Cury JA, Paes Leme AF, Tabchoury CM, Del Bel Cury AA, Rosalen PL, et al. Effect of sucrose containing iron (II) on dental biofilm and enamel demineralization in situ. Caries Res. 2005;39(2):123-9

17- Rao SVC. Preparation of solid solutions of calcium and iron hydroxylapatites. J Inst Chem Calcutta. 1974;46:30-1.

18- Rosalen PL, Pearson SK, Bowen WH. Effects of copper, iron and fluoride co-crystallized with sugar on caries development and acid formation in desalivated rats. Arch Oral Biol. 1996; 41(11):100310 .

19- Sales-Peres SHC, Pessan JP, Buzalaf MAR. Effect of an iron mouthrinse on enamel and dentine erosion subjected or not to abrasion: an in situ/ex vivo study. Arch Oral Biol. 2007;52(2):128-32.

20- Sales-Peres SHC, Magalhães AC, Machado MAAM, Buzalaf MAR. In vitro evaluation of the erosive potential of five soft drinks. Eur $\mathrm{J}$ Dent. In press 2007

21- Takuma S, Ogiwara H, Suzuki H. Electron-probe and electron microscope studies of carious dentinal lesions with a remineralized surface layer. Caries Res. 1975;9(4):278-85.

22- Torell P. Iron and dental caries. Swed Dent J. 1988;12(3):11324 